\title{
Vasopressin secretion in progressive autonomic failure: evidence for defective afferent cardiovascular pathways
}

\author{
TDM WILLIAMS, SL LIGHTMAN, ${ }^{*}$ R BANNISTER
}

From the Department of Medicine, Charing Cross and Westminster Medical School, Westminster Hospital and the Neurology Department, ${ }^{*}$ St. Mary's Hospital, London, UK.

SUMMARY Patients with progressive autonomic failure with multiple system atrophy show a severely blunted response of plasma arginine vasopressin to the stimulus of head-up tilt. Whether this could be due to lesions either at one or more sites within ascending neural pathways from cardiovascular stretch receptors in the thorax or, alternatively, to lesions affecting vasopressin secreting cells within the hypothalamus was investigated. The arginine vasopressin response to an intravenous infusion of hypertonic saline was determined in six patients with progressive autonomic failure. The mean plasma concentration of arginine vasopressin rose from 1.0 to $3.7 \mathrm{pmol} / \mathrm{l}$, a change comparable to that observed in normal controls. This demonstrates normal functioning of the efferent connections from the osmoreceptors within the hypothalamus and suggests that the loss of vasopressin response to head-up tilt is due to lesions in ascending pathways from cardiovascular receptors. There was a significant rise in mean blood pressure during the infusions on patients with progressive autonomic failure, a change which was not observed with the controls. This may have been at least partly caused by the rise in circulating arginine vasopressin concentrations, since these patients have been reported to be extremely sensitive to the pressor effects of arginine vasopressin.

Plasma levels of arginine vasopressin normally rise in response to either an increase in plasma tonicity relayed from the central osmoreceptors within the hypothalamus or to a reduction in stretch in cardiovascular receptors within the thorax. The afferent pathways from these stretch receptors travels via the vagus nerve to the nucleus tractus solitarius (see fig) which projects to the paraventricular nucleus of the hypothalamus. ${ }^{12}$

Central nervous system lesions have been found at several sites in patients with progressive autonomic failure. The dorsal vagal nucleus and the locus coeruleus are almost always sites of neuronal loss. ${ }^{3}$ It has become apparent, however, that neurochemical abnormalities may be more sensitive than neuronal loss at necropsy in the assessment of CNS damage in this disease. ${ }^{4}$ Of particular interest has been the finding of a marked loss of noradrenaline

Address for reprint requests: Dr Stafford Lightman, Westminster Hospital, 17 Page St, London SW1P 2AP, UK.

Received 30 May 1984

Accepted 10 July 1984 and dopamine in both the hypothalamus and the locus coeruleus. It has recently been demonstrated that in the rat the noradrenergic projection from the locus coeruleus to the periventricular zone of the paraventricular nucleus is of great importance in the

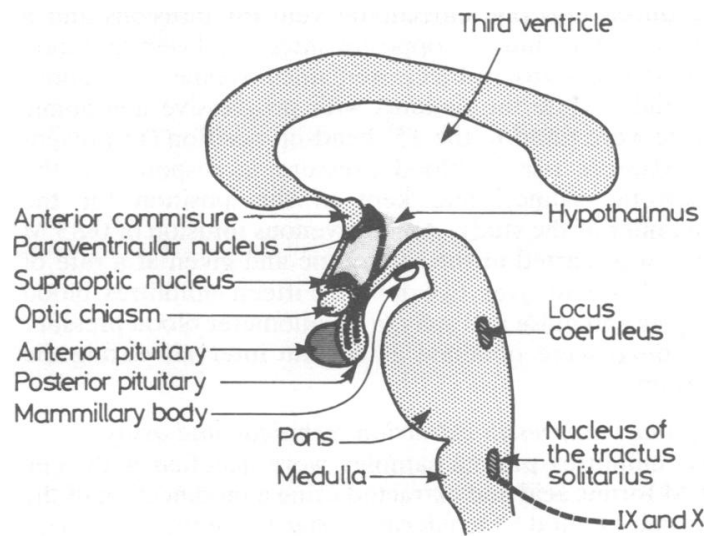

Fig CNS regions associated with vasopressin secretion. 
arginine vasopressin response to cardiovascular stimuli. $^{5}$

It has been shown that compared with normal subjects patients with progressive autonomic failure with multiple system atrophy show a severely blunted response of plasma arginine vasopressin to the stimulus of head-up tilt. ${ }^{67}$ If the lack of arginine vasopressin response is due to interruption of brainstem afferent pathways, perhaps in the locus coeruleus, the arginine vasopressin response to hypertonic saline should be preserved. If, however, the lack of arginine vasopressin response to tilt is due to an abnormality at the level of the hypothalamus, one would also expect an abnormality of osmotically stimulated arginine vasopressin release.

In the present study we investigated these alternative hypotheses by determining the arginine vasopressin response to an infusion of hypertonic saline in patients with progressive autonomic failure and comparing this with the response in normal subjects.

\section{Methods}

\section{Patients and controls}

The study was approved by St Mary's Hospital Ethics Committee and was performed on three male and three female patients aged between 55 and 74 years. Patients gave their informed consent. All had progressive autonomic failure characterised by a blocked response to Valsalva's manoeuvre and marked postural hypotension and, in addition, three patients had the central neurological features of multiple system atrophy. The control group consisted of six normal subjects. All control subjects and two of the patients had not received any medications for at least one month before the study. The remaining four patients (three receiving $9 \alpha$-fluoro-hydrocortisone and one also receiving dihydroergotamine) had their medications discontinued at least 24 hours before the study. Subjects were fasted for 12 hours overnight. They lay supine on a tilt table for $\mathbf{3 0} \mathrm{min}$. During this time a cannula was introduced into one antecubital vein for infusions and a similar cannula into the opposite antecubital vein for blood sampling. Control subjects remained supine throughout the study, while the patients with progressive autonomic failure were tilted to the $15^{\circ}$ head-up position (to prevent an excessive rise in blood pressure in response to the hypertonic saline), and kept in this position for the remainder of the study. An intravenous infusion of $0.85 \mathrm{M}$ saline was started at the same time and given at a rate of $0.05 \mathrm{ml} / \mathrm{kg} / \mathrm{min}$ over two hours. Fifteen millilitres blood samples and pulse and sphygmomanometer blood pressure recordings were obtained at $\mathbf{3 0}$ min intervals during the infusion.

\section{Arginine vasopressin extraction technique and assay}

Two millilitres plasma samples were acidified with $3 \mathrm{ml}$ $0.1 \mathrm{M}$ formic acid and extracted using a modification of the Sep-Pak method. ${ }^{8}$ Octadecasilyl silica columns (C18 SepPaks, Waters Associates, Northwich) attached to a multichannel pump (Watson-Marlow, Falmouth) were first regenerated with $95 \%$ methanol $5 \% 0 \cdot 1 \mathrm{M}$ formic acid $(3 \mathrm{ml})$ followed by $0.1 \mathrm{M}$ formic acid $(3 \mathrm{ml})$ and the acidified samples were passed on to the columns at $1 \mathrm{mV}$ min and washed with $0.1 \mathrm{M}$ formic acid $(3 \mathrm{ml})$. Elution with $95 \%$ methanol $/ 5 \% 0.1 \mathrm{M}$ formic acid $(3 \mathrm{ml})$ was followed by solvent evaporation in a vacuum centrifuge (Speed Vac Concentrator, Uniscience, London). The residue was taken up in $220 \mu \mathrm{l}$ radioimmunoassay buffer $(0.1 \mathrm{M}$ Tris acidified to $\mathrm{pH} 7.4$ with $\mathrm{HCl}$ and containing $2 \mathrm{~g} / \mathrm{l}$ Bovine Serum Albumin) for subsequent assay in $100 \mu \mathrm{l}$ duplicates. Extraction yield, calculated from extracting ${ }^{125}$ I-labelled arginine vasopressin added to plasma, was $94 \% \pm 2 \%$ (mean \pm S.D., $n=10)$. Arginine vasopressin was measured by a highly specific and sensitive radioimmunoassay using $100 \mu$ l each of: (1) 1st International Standard for arginine vasopressin, (2) ${ }^{125}$ I-labelled arginine vasopressin prepared by the Iodogen method ${ }^{9}$ and purified on DEAE-Sephadex A-25 to produce labelled arginine vasopressin with a specific activity of $1800 \mathrm{ci} / \mathrm{g}$ and (3) specific arginine vasopressin antiserum at a final dilution of $1 / 250,000$. Tracer was added after 48 hours pre-incubation of antibody and standard, and incubation was continued for a further 24 hours. Bound tracer was separated from the free fraction by precipitating with chilled ethanol, centrifuging and decanting the supernatant. $50 \%$ inhibition of tracer binding occurred with $0.3 \mathrm{fmol}$ standard arginine vasopressin. Coefficients of variation of $0 \omega$ control samples ( $2 \mathrm{fmol}$ ) were $14 \%$ (intra-assay) and $17 \% 0$ (inter-assay), $\mathrm{n}=8$.

\section{Other measurements}

Plasma osmolality was measured using an automatic cryoscopic osmometer (Osmomat 030, Gonotec, Berlin). Mean blood pressure was calculated by adding one-third of the pulse pressure to the diastolic blood pressure (Korotkoff phase 5). Two-way analysis of variance was used to test statistical significance of changes in plasma sodium, osmolality, arginine vasopressin and blood pressure during the infusion. Unpaired $t$ tests were used to test for any differences in these parameters between groups at each time interval.

\section{Results}

There were no significant differences in the values of plasma sodium, osmolality, arginine vasopressin and blood pressure throughout the infusion between patients with progressive autonomic failure alone and those with the additional features of multiple system atrophy. All six patients, therefore, formed a homogenous group in terms of these responses to a hypertonic saline infusion.

Basal levels of arginine vasopressin in the patients $(1.0 \pm 0.2 \mathrm{pmol} / \mathrm{l})$ were appropriate for plasma osmolality and sodium concentration (table). There was a progressive rise in arginine vasopressin levels in all patients during the hypertonic saline infusion, reaching a mean value of $3.7 \pm 0.6 \mathrm{pmol} / \mathrm{l}$ after two hours $(\mathrm{p}<0.01)$. Significant increases were also found in plasma sodium and osmolality $(p<0.01$ in 
Table Mean values $( \pm S E M)$ during hypertonic saline infusion in six patients with progressive autonomic failure and six control subjects

\begin{tabular}{|c|c|c|c|c|c|c|c|c|c|c|}
\hline \multirow[t]{2}{*}{ Table (min) } & \multicolumn{5}{|l|}{ Patients } & \multicolumn{5}{|c|}{ Controls } \\
\hline & 0 & 30 & 60 & 90 & 120 & 0 & 30 & 60 & 90 & 120 \\
\hline \multirow[t]{2}{*}{ Sodium (mmol/l) } & 140 & 142 & 143 & 145 & 147 & 140 & 142 & 144 & 145 & 146 \\
\hline & $2 \cdot 0$ & 2.0 & $1 \cdot 3$ & $1 \cdot 7$ & $2 \cdot 1$ & 1.6 & $1 \cdot 2$ & 1.6 & $1 \cdot 0$ & 1.4 \\
\hline Osmolality $(\mathrm{m} 0 \mathrm{smol} / \mathrm{kg})$ & 292 & 297 & $\begin{array}{l}299 \\
1.6\end{array}$ & 306 & 306 & 289 & 294 & 296 & 299 & 302 \\
\hline \multirow{2}{*}{ AVP (pmol/l) } & $\begin{array}{l}2.7 \\
1.0\end{array}$ & $\begin{array}{l}2 \cdot 0 \\
1 \cdot 3\end{array}$ & $\begin{array}{l}1.0 \\
1.8\end{array}$ & $\begin{array}{l}3 \cdot 3 \\
2 \cdot 8\end{array}$ & $\begin{array}{l}3.5 \\
3.7\end{array}$ & $\begin{array}{l}1.4 \\
1.6\end{array}$ & $\begin{array}{l}0.3 \\
3 \cdot 4\end{array}$ & $\begin{array}{l}0.8 \\
3.3\end{array}$ & $\begin{array}{l}1 \cdot 1 \\
3 \cdot 5\end{array}$ & $\begin{array}{l}1 \cdot 4 \\
4 \cdot 2\end{array}$ \\
\hline & 0.2 & $0 \cdot 2$ & 0.3 & 0.4 & 0.6 & 0.8 & 1.2 & 0.9 & 0.9 & 0.8 \\
\hline \multirow{2}{*}{$\begin{array}{l}\text { Mean blood pressure } \\
(\mathrm{mm} \mathrm{Hg})\end{array}$} & 96 & 100 & $104^{*}$ & $108 \dagger$ & $112 \ddagger$ & 85 & 86 & $86^{*}$ & $85 t$ & $84 \ddagger$ \\
\hline & $7 \cdot 0$ & $5 \cdot 5$ & 3.9 & $3 \cdot 8$ & $2 \cdot 8$ & $5 \cdot 4$ & 5.9 & $5 \cdot 2$ & $5 \cdot 6$ & $4 \cdot 9$ \\
\hline
\end{tabular}

${ }^{*} \mathrm{p}<0.05, \dagger \mathrm{p}<0.01, \neq \mathrm{p}<0.001$ (unpaired t-tests) for between group comparisons.

each case), and mean blood pressure rose from $96 \pm$ $7.0 \mathrm{~mm} \mathrm{Hg}$ to $112 \pm 2.8 \mathrm{~mm} \mathrm{Hg}(\mathrm{p}<0.01)$.

The six normal controls showed significant increases in plasma sodium osmolality and arginine vasopressin during the infusion $(\mathrm{p}<0.01$ in each case). In addition, levels of each of these parameters in the controls at each time interval did not differ significantly from corresponding levels in the patient group (table). In marked contrast, however, there was no change in mean blood pressure during the infusion in the control group $(85 \pm 5.4 \mathrm{~mm} \mathrm{Hg}$ at zero time and $84 \pm 4.9 \mathrm{~mm} \mathrm{Hg}$ at 2 hours), so that mean blood pressures at 60,90 and 120 min were significantly lower than in the patient group ( $\mathrm{p}<$ $0.05, p<0.01$ and $p<0.001$, respectively).

\section{Discussion}

Like Zerbe et al, ${ }^{7}$ we have found normal basal plasma osmolality and arginine vasopressin levels in patients with progressive autonomic failure. In addition, we have shown that the hypothalamoneurohypophyseal system of these patients responds normally to an osmotic stimulus implying intact posterior pituitary function. This is in contrast to studies using the stimulus of head-up tilt, where compared with normal subjects, patients with progressive autonomic failure show a severely blunted response of plasma arginine vasopressin despite the additional stimulus to vasopressin secretion of considerable postural hypotension. ${ }^{6}$

It is clearly important to localise the site of lesions causing impairment of arginine vasopressin release since this could provide an insight into a rational therapeutic approach to the incapacitating symptoms of orthostatic hypotension.

Patients with progressive autonomic failure can be divided into two groups. ${ }^{10}$ The first is characterised clinically as having progressive autonomic failure alone or in combination with Parkinson's disease. Pathologically, this group have cell loss in the intermedio-lateral columns, the substantia nigra and other brainstem nuclei including the dorsal vagal nucleus (seven out of 10 reported cases) and the locus coeruleus (six out of 10 cases). The second group, with clinical progressive autonomic failure and multiple system atrophy, also have cell loss in the intermediolateral columns and in brainstem nuclei including the dorsal vagal nucleus ( 24 out of 41 reported cases) and the locus coeruleus ( 28 out of 48 cases). Three of our patients had progressive autonomic failure alone and the others had progressive autonomic failure with multiple system atrophy. These two groups responded in the same way to hypertonic saline. From the pathological findings described above, it seems that the critical central progressive autonomic failure lesions which affect arginine vasopressin release are similar in the two groups.

Noradrenergic projections from the A1, A2 and A6 noradrenergic cell groups in the brainstem project to the paraventricular nucleus. ${ }^{1}$ In recent studies using the rat as a model, it has been found that only those fibres travelling in the dorsal noradrenergic pathway in the midbrain to the hypothalamus are necessary both for the arginine vasopressin response to haemorrhage and to mediate the inhibition of arginine vasopressin release by clonidine. ${ }^{5}$ This pathway has a major input from cell bodies in the locus coeruleus. It is, therefore, of considerable interest that histological evidence of damage to the locus coeruleus is frequent in progressive autonomic failure and that Spokes $\mathrm{et} \mathrm{al}^{4}$ have also shown loss of noradrenaline and dopamine in this nucleus (see fig). Head-up tilt results in a fall in plasma volume which is detected by stretch receptors in the left atrium. This normally results in arginine vasopressin secretion, the afferent pathway reaching the brainstem via the vagus nerve." The lack of arginine vasopressin response to head-up tilt in progressive autonomic failure indicates an afferent defect in addition to the sympathetic efferent lesions known to be present. The locus coeruleus and its projections are likely to be of major importance in this role but in view of the lesions at other sites in progressive aut- 
onomic failure, damage to other pathways may also be important. We agree with Zerbe et al ${ }^{7}$ that arginine vasopressin response to head-up tilt can serve as a test for the integrity of ascending cardiovascular pathways. Exclusive tests of the afferent part of autonomic central reflex arcs are difficult to devise, and the present test is comparable to that of hand blood flow responses to direct and indirect heating. ${ }^{12} 13$

Abnormal sensitivity to the pressor effects of arginine vasopressin in progressive autonomic failure was first reported by Wagner and Braunwald. ${ }^{14}$ Lysine vasopressin has the same effect in these patients. ${ }^{15}$ Möhring et al ${ }^{16}$ found that patients with progressive autonomic failure are sensitive to the pressor effects of infused arginine vasopressin at plasma concentrations in the physiological range (up to $5 \mathrm{pmol} / \mathrm{l}$ ), whereas an equipressor dose in normals is about 1,000 times greater. Lesions at other sites in the afferent pathways can also cause increased sensitivity to the pressor effects of arginine vasopressin, as demonstrated by Montani et al $^{17}$ in baroreceptor denervated dogs. These workers also showed that infusion of hypertonic saline into these animals caused an increase in blood pressure which correlated with the rise in plasma arginine vasopressin.

The rise in blood pressure during hypertonic saline infusion in patients with progressive autonomic failure, but not in normal controls, is of considerable interest. It is known that sympathetic denervation results in increased numbers of catecholamine receptors with consequent supersensitivity to circulating catecholamines, ${ }^{18}$ and it is quite possible that alterations in vasopressin receptor numbers and affinity may also occur. Indeed, there is now some evidence that a vasopressin-like peptide exists in sympathetic nerves ${ }^{19}$ and it may be that the diminution of this peptide in progressive autonomic failure is the cause of the increased sensitivity to exogenous vasopressin. This sensitivity to arginine vasopressin may indeed have haemodynamic effects in patients with progressive autonomic failure, and the loss of arginine vasopressin secretion during head-up tilt may contribute to their orthostatic hypotension.

T.D.M. Williams gratefully acknowledges a Sir Jules Thorn Research Fellowship in Neuroendocrinology. We also thank Dr. P.H. Baylis for his kind gift of antiserum.

\section{References}

' Sawchenko PE, Swanson LW. Central noradrenergic pathways for the integration of hypothalamic neuroendocrine and autonomic responses. Science 1981;214:685-7.

${ }^{2}$ Sawchenko PE, Swanson LW. The organisation of noradrenergic pathways from the brainstem to the paraventricular and supraoptic nuclei in the rat. Brain Res Rev 1982;4:275-325.

${ }^{3}$ Oppenheimer D. In: Bannister R, ed, Autonomic Failure. Oxford Medical Publications, 1983. Neuropathology of Progressive Autonomic Failure, Chapter 14, 267-83.

${ }^{4}$ Spokes EG, Bannister R, Oppenheimer DR. Multiple system atrophy with autonomic failure: clinical, histological and neurochemical observations on four cases. J Neurol Sci 1979;43:59-82.

${ }^{5}$ Lightman SL, Everitt BJ, Todd K. Ascending noradrenergic projections from the brainstem; evidence for a major role in the regulation of blood pressure and vasopressin secretion. Exp Brain Res 1984;55:14551.

- Puritz R, Lightman SL, Wilcox CS, Forsling M, Bannister $\mathbf{R}$. Blood pressure and vasopressin in progressive autonomic failure. Brain 1983;106:503-11.

7 Zerbe RL, Henry DP, Robertson GL. Vasopressin response to orthostatic hypotension. Am J Med 1983;74:265-71.

${ }^{8}$ La Rochelle Jr F T. North WE, Stern P. A new extraction of arginine vasopressin from blood: the use of octadecasilyl silica. Pfügers Archives 1980;387:7981.

${ }^{9}$ Salacinski P, Hope J, McLean C, et al. A new simple method which allows incorporation of radio-iodine $\mathrm{N}$ into proteins and peptides without damage. $J$ Endo-尺 crinol 1979;81:131P.

${ }^{10}$ Bannister R. Autonomic Failure. Oxford Medical Publications, 1983. Clinical Features of Progressive Autonomic Failure, Chapter 5, 67-73.

" Hainsworth R, Kidd C, Linden RJ. Cardiac Receptors. Cambridge University Press, 1979.

12 Bannister R, Ardill L, Fentem P. Defective autonomic control of blood vessels in idiopathic orthostatic hypotension. Brain 1967;90:725-46.

${ }^{13}$ Kerslake D, Cooper K. Vasodilatation in the hand in response to heating the skin elsewhere. Clinical Sci 1950;9:31-47.

14 Wagner Jr HN, Braundwald E. The pressor effect of the antidiuretic principle of the posterior pituitary in orthostatic hypotension. J Clin Invest 1956;35:141218.

15 Bannister R, Ardill L, Fentem. An assessment of various methods of treatment of idiopathic orthostatic hypotension. $Q$ J Med 1969;38:377-95.

${ }^{16}$ Möhring J, Glänzer K, Maciel Jr JA, et al. Greatly enhanced pressor response to antidiuretic hormone in patients with impaired cardiovascular reflexes due to idiopathic orthostatic hypotension. J Cardiovasc Pharmacol 1980; 2:367-76.

${ }^{17}$ Montani JP, Liard JF, Schoun J, Möhring J. Hemodynamic effects of exogenous and endogenous vasopressin at low plasma concentrations in conscious dogs. Circ Res 1980;47:346-55.

${ }^{18}$ Bannister R, Davies IB, Holly E, Rosenthal T, Sever P. Defective cardiovascular reflexes and supersensitivity to sympathomimetic drugs in autonomic failure. Brain 1979; 102: 163-76.

${ }^{19}$ Hanley MR, Benton HP, Lightman SL, et al. A vasopressin-like peptide in the mammalian sympathetic nervous system. Nature 1984;309:258-61. 